\title{
Diacronie
}

Studi di Storia Contemporanea

$\mathrm{N}^{\circ} 24,4 \mid 2015$

Le dittature militari: fisionomia ed eredità politica

\section{La revolución Argentina es cosa seria: el humor político en la coyuntura del golpe de estado de junio de 1966}

\section{Bettina Favero y Francisco Mosiewicki}

\section{(2) OpenEdition \\ Journals}

Edición electrónica

URL: http://journals.openedition.org/diacronie/3641

DOI: $10.4000 /$ diacronie.3641

ISSN: 2038-0925

Editor

Association culturelle Diacronie

Referencia electrónica

Bettina Favero y Francisco Mosiewicki, «La revolución Argentina es cosa seria: el humor político en la coyuntura del golpe de estado de junio de 1966 », Diacronie [En línea], № 24, 4 | 2015, documento 3, Publicado el 29 diciembre 2015, consultado el 10 diciembre 2020. URL : http://

journals.openedition.org/diacronie/3641; DOI : https://doi.org/10.4000/diacronie.3641 


\title{
Diacronie
}

N. 24 | 4|2015 Le dittature militari: fisionomia ed eredità politica

3/

\section{La revolución Argentina es cosa seria: el humor político en la coyuntura del golpe de estado de junio de 1966}

\author{
Bettina FAVERO, Francisco MOSIEWICKI *
}

En junio de 1966 mediante un golpe de estado liderado por el general Onganía, se instauró un gobierno que con el tiempo devino en "burocrático autoritario", sin un tiempo límite, con intenciones de largo plazo y sumando nuevas prohibiciones a las ya proscripciones al peronismo. De esta forma, se rompía una vez más la gradual transición hacia la democracia en la Argentina. El propósito de este artículo es indagar desde el humor político, el modo en que el proceso que culminó con la autodenominada "Revolución Argentina", era apreciado y representado en las tiras cómicas y artículos de una revista en particular. La fuente principal con la que se trabajará son los últimos números publicados de «Tía Vicenta». La revista, dejó de aparecer el 17 de julio de 1966, pocas semanas después de la asunción del general Onganía como presidente de la Nación. Fue clausurada "por falta de respeto hacia la autoridad y la investidura jerárquica”, específicamente por representar al presidente como una morsa.

\section{Introducción}

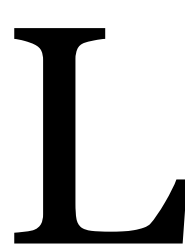

n junio de 1966 mediante un golpe de estado liderado por el general Onganía, se instauró un gobierno militar sin un tiempo límite, con intenciones de largo plazo y sumando nuevas prohibiciones a las ya proscripciones al peronismo. De esta forma, se rompía una vez más la 
gradual transición hacia la democracia en la Argentina.

El propósito de este artículo es indagar desde el humor político, el modo en que el proceso que culminó con la autodenominada "Revolución Argentina", era apreciado y representado en las tiras cómicas y artículos de una revista en particular. Así, se buscará relevar los números de la revista que hacen referencia al golpe de 1966 como también analizar, a partir de los mismos, el clima político de la época.

La fuente principal con la que se trabajará son los últimos números publicados de «Tía Vicenta». La revista, dejó de aparecer el 17 de julio de 1966, pocas semanas después de la asunción del general Onganía como presidente de la Nación. Fue clausurada "por falta de respeto hacia la autoridad y la investidura jerárquica", específicamente por representar al presidente como una morsa.

El humor respecto de las prácticas, acciones y jergas políticas, posibilitará la comprensión de aspectos de la política sesentista en un medio gráfico que hacía uso de la lógica del disparate, convocando a su comunidad de lectores a reírse de los gobiernos de turno. El estudio y análisis histórico del humor político se ha desarrollado y expandido en los últimos años en la historiografía argentina1. Esto nos ubica en una línea de trabajo historiográfico que tiene como fuente principal las revistas de humor de toda una época, en este caso signada por la alternancia de gobiernos democráticos y militares. El uso de publicaciones humorísticas nos permitirá complejizar el análisis histórico de un momento importante en la historia de nuestro país como también observar la forma en que eran reinterpretadas las situaciones y acciones políticas y militares de ese momento a través del mismo. Partimos de la idea que una publicación, en este caso humorística, es el eco de una sociedad pero también tiene líneas ideológicas marcadas que indican un camino. Las fuentes con las que hemos trabajado



\footnotetext{
1 Tomamos como referencia los trabajos de: MATALLANA, Andrea, Humor y política. Un estudio comparativo de tres publicaciones de humor político, Buenos Aires, Eudeba, 1999; BURKART, Mara, «Caricatura política en el Cono Sur: entre la radicalización política y las dictaduras militares», in Revista contemporânea : Dossiê convidado: caricatura política en el cono sur, IV, 4, 2/2014, pp. 1-11; GENÉ, Marcela, «Risas, sonrisas y carcajadas en tiempos de Peron: pasando revista al humor político», in SORIA, Claudia, ROCCA, Paola, DIELEKE, Edgardo (eds.), Políticas del sentimiento. El peronismo y la construcción de la Argentina moderna, Buenos Aires, Prometeo, 2010; GENÉ, Marcela, Atrapados por la imagen. Arte y política en la cultura impresa argentina, Buenos Aires, Ed-hasa, 2013; GANDOLFO, Amadeo, «Tía Vicenta, entre Frondizi y Onganía (1957-1966)», in Caiana. Revista electrónica de Historia del Arte y Cultura Visual del Centro Argentino de Investigadores de Arte (CAIA), 2, 1/2013, pp. 1-13; LEVIN, Florencia, Humor político en tiempos de represión. Clarín, 1973-1983, Buenos Aires, S. XXI Ed., 2013; LEVIN, Florencia, Humor gráfico. Manual de uso para la historia, Los Polvorines, UNGS, 2014.

${ }^{2}$ Sobre este tipo de fuentes Carlo Ginzburg dice que «hay que admitir que cuando se habla de filtros e intermediarios deformantes tampoco hay que exagerar. El hecho que una fuente no sea
} 
revista, colaboradores y línea político - ideológica - con los que será posible reconstruir un clima político que se repetía asiduamente: el previo a un golpe de estado.

\section{Una ventana al marco histórico}

El golpe de Estado que pondría fin a la segunda presidencia de Juan Domingo Perón, ocurrido en septiembre de 1955, abriría un período particular en la Argentina en lo referente al funcionamiento de la política.

Varios han sido los calificativos empleados para designar a un proceso que finalizaría recién con el triunfo electoral de Héctor Cámpora en mayo de 1973. Tcach ${ }^{3}$ deja constancia de cuatro de ellos: por un lado es posible emplear el término de "semidemocracia", atribuido al funcionamiento electoral del país a pesar de la proscripción del peronismo; en segundo lugar, se ha usado el calificativo "parlamento negro”, en relación a la forma en que la lógica política se desarrollaba por canales no institucionales (tal es el caso de los planteos militares); en tercer lugar es llamado "empate", dado el equilibro hegemónico existente entre los distintos actores políticos, allí donde cada uno tenía la capacidad de obstruir el libre desarrollo de los proyectos de los demás, pero carecía de la capacidad de encausar los propios sin el acuerdo con las otras fuerzas; por último, se lo ha llamado "juego imposible", ya que durante este período las posibilidades de victoria electoral sin el voto del peronismo (por entonces proscrito) se acercaban a la nulidad, así como también se imposibilitaba mantener un gobierno civil sin el visto bueno de las Fuerzas Armadas (FFAA).

Potash $^{4}$ en su momento utilizó otra variable para explicar la alternancia entre gobiernos civiles y militares (sin dejar de lado la cuestión peronista), es decir, la estabilidad del sistema democrático en nuestro país, tomando como base la "confianza" que tanto los actores civiles como militares eran capaces de depositar en los gobiernos constitucionales y en el parlamento a la hora de poner en práctica soluciones eficaces a los diversos problemas que acontecían en la agenda nacional. Por tanto, la creciente aceleración con que dichos cambios de poder se fueron produciendo a lo largo del siglo

objetiva (tampoco un inventario lo es) no significa que sea inutilizable». Cfr. GINZBURG, Carlo, El queso y los gusanos. El cosmos según un molinero del siglo XVI, Barcelona, Muchnik Editores, 1991.

3 Véase: TCACH, César, «Golpes, proscripciones y partidos políticos», in JAMES, Daniel, Violencia, proscripción y autoritarismo (1955-1976), t. IX, Buenos Aires, Sudamericana, 2007.

4 POTASH, Robert, El ejército y la política en la Argentina 1945-1962. De Perón a Frondizi, Buenos Aires, Sudamericana, 1981. 
XX5 , se debió, en parte, no sólo a la "falta de fe" de los actores civiles en el proceso democrático, sino también a la firme creencia, por parte de las FFAA, de ser el factor que la sociedad necesitaba para hacer que la sociedad retorne al cauce deseado cuando tomaba el camino “incorrecto”. Así, el poder militar se convertía en juez de la sociedad a la que servía, a pedido de ella misma.

En este sentido, la revolución de 1955 implicaba para las fuerzas antiperonistas el retorno a una sociedad democrática que ya en la crisis de 1952 parecía perdida frente a la debacle del gobierno de Perón. Si bien la facción "legalista" dentro no aprobó la medida, tampoco realizó ninguna acción para impedir el golpe ${ }^{6}$.

En un primer momento, las intenciones de la cabeza del gobierno de facto (el general Lonardi, quien a su vez había dirigido la infantería y artillería desde Córdoba) difirieron en un tema crucial que marcaría el camino a seguir del gobierno de la "Libertadora": ¿Qué hacer con el peronismo? El discurso pronunciado por el mandatario una vez ubicado en la Casa Rosada donde anunció que no habría "ni vencedores ni vencidos", generó la suficiente animadversión en la facción antiperonista, al punto que menos de dos meses después Lonardi presentó su renuncia y fue sucedido por la fórmula Aramburu-Rojas.

En cuanto al interior de las FFAA, los acontecimientos ocurridos a posteriori del golpe marcarían una división entre legalistas y antiperonistas que se iría profundizando cada vez más. Esta brecha, a su vez, marcaría a fuego a la sociedad civil a tal punto que aún hoy en día posible dividir a la sociedad entre aquellos que adscriben y quienes difieren del ideario peronista.

Habiéndose concretado el golpe, los sectores civiles que apoyaron la destitución no tardaron en reclamar el retorno del poder político y la realización de nuevos comicios electorales. Cabe aclarar, como lo remarca Potash que dicha actitud se había vuelto una costumbre por parte de los sectores civiles que apoyaban los golpes, allí donde esperaban por parte de las FFAA la realización de una «cirugía política»7 que extirpase el gobierno que no funcionaba de acuerdo a sus deseos y dejase el camino libre para la instauración de otro.

De esta manera, el gobierno de la Unión Cívica Radical Intransigente (UCRI), encabezado por Arturo Frondizi marcó el parcial "retorno de la democracia” en 1958. A pesar de ello, ni el partido político que se hizo con el oficialismo, ni aquellos que

\footnotetext{
5 Nótese, tal como lo afirma el autor que a partir de 1930 hasta 1983, los gobiernos civiles fueron cada vez más cortos, mientras que los períodos de gobierno militar se prolongaron cada vez más. ${ }^{6}$ Grupo de militares caracterizados por primar la legalidad constitucional a la lucha ideológica. Más tarde sería la facción identificada como los "azules".

7 POTASH, Robert, op. cit., p. 507.
} 
integraban la oposición tenían aún la fuerza suficiente como para garantizar un régimen democrático que perdurara en el tiempo. Con las elecciones de marzo de 1962 en las que nueve candidatos justicialistas se alzaron con la victoria, la falta de apoyo de los partidos políticos opositores y de las fuerzas militares al gobierno frondizista era un hecho ${ }^{8}$. Tras soportar treinta y dos planteos militares y verse obligado a cortar las relaciones con Cuba (luego de la visita del "Che" Guevara) e intervenir políticamente las provincias luego de la derrota de marzo del $62^{9}$, fue puesto bajo arresto y recluido en la isla Martín García el día 29 de ese mismo mes.

Con las elecciones de marzo de 1962 en las que nueve candidatos justicialistas se alzaron con la victoria, la falta de apoyo de los partidos políticos opositores y de las fuerzas militares al gobierno frondizista era un hecho.

El gobierno de la UCRI es sucedido en la presidencia por José María Guido, quien hasta entonces había sido presidente del senado. Este interregno se caracterizó por presentar una «renovada influencia de la Argentina tradicional [...], liberal en lo económico, conservadora en lo político y reaccionaria en lo cultural»10. $\mathrm{El}$ "problema peronista" siguió sin resolverse y las posibles soluciones al mismo venían de la mano de las armas en menoscabo de la vía electoral. En este marco, el recrudecimiento de las medidas antiperonistas llevadas a cabo por las facciones antiintegracionistas de las FFAA tuvo un saldo cruento a nivel social, que se manifestó tanto en la Muerte de Felipe Vallese ${ }^{11}$, como en atentados perpetrados por grupos armados de extrema derecha.

Las medidas tendientes a revertir esta situación fueron encausadas por la facción legalista (integracionista) de las fuerzas militares. Así, el general Onganía solicitó la destitución tanto del Comandante en Jefe del Ejército, como del Jefe de Estado Mayor (Lorio y Labayru, respectivamente), actitud que fue respaldada por el comandante de la guarnición de Campo de Mayo, el general Julio Alsogaray. De esta manera, el enfrentamiento entre los rebeldes integracionistas, que pasarían a ser conocidos como los azules y los antiintegracionistas, colorados, se decidió por medio de las armas,

\footnotetext{
8 Para la reconstrucción histórica de este período, se han tomado como referencia los siguientes autores: NOVARO, Marcos, Historia de la Argentina. 1955-2010, Buenos Aires, S. XXI Ed., 2010; BEN PLOTKIN, Mariano (Coord.), Argentina. La búsqueda de la democracia. 196o200o, Buenos Aires, Taurus, 2012.

9 Tras la exclusión del Partido Justicialista (PJ) de la arena electoral luego de la renovación de las legislaturas provinciales a principios del '59 y el anuncio de Perón de la "traición de Frondizi”, el poder ejecutivo debió afrontar en las elecciones provinciales de marzo de 1962 a una victoria mayoritaria de la Unión Popular (nombre bajo el que se aglutinaba la mayoría de las fuerzas peronistas por entonces).

${ }^{10} \mathrm{TCACH}$, César, op. cit., p. 38.

${ }^{11}$ Joven de 22 años, delegado de la Unión Obrera Metalúrgica, torturado y asesinado por la policía de la provincia de Buenos Aires.
} 
imponiéndose victoriosos los rebeldes luego de cuatro días de "pequeños combates". Debe ser tenido en cuenta el hecho de que la Marina se abstuvo de participar en esta ocasión.

Tras la derrota de la facción colorada, Onganía fue designado Comandante en Jefe del Ejército y fue puesto en práctica un plan de "integración subordinada del peronismo", que conllevo a la legalización de la Unión Popular, sucesos que no agradaron al ex vicepresidente y almirante (R) Rojas, quien preparaba un nuevo golpe, a gestarse el 2 de abril de 1963 .

Los colorados no habían sido vencidos en forma definitiva, pero las jornadas de septiembre de 1962, habían cambiado en forma radical la cúpula del Ejército. Así como remarca Rouquié ${ }^{12}$, ciento cuarenta oficiales superiores fueron pasados a retiro, purga que fue llevada a cabo con determinación por el secretario de Guerra del presidente Guido: el teniente general Benjamín Rattenbach.

El año 1963 será año electoral, Arturo Illia (Unión Cívica Radical del Pueblo) fue elegido presidente de la Nación con el 25\% de los votos. Un muy bajo respaldo electoral que se veía reflejado en el porcentaje de votos en blanco (21\%) correspondiente al peronismo proscripto. Así, Illia comenzó su presidencia que duraría poco menos de tres años, truncada por un nuevo golpe militar encabezado por el general Julio Alsogaray y que designaría como presidente de facto al teniente general Juan Carlos Onganía. El gobierno pese a los buenos resultados económicos logrados tuvo muy baja aprobación desde la opinión pública que se bipolarizaba entre la "revolución social" que desafiaba Perón desde el exilio y la "revolución nacional" dirigida por las Fuerzas Armadas. Ésta última se impondría en función de la idea que las mismas eran quienes podrían imponer el orden y acelerar el desarrollo.

El golpe de Estado del año 1966, llamado "Revolución Argentina” llevó al general Onganía a ejercer un gobierno "técnico" y "apolítico". Sus objetivos a largo plazo indicaban que bajo el nuevo orden, el país viviría un tiempo económico, luego un tiempo social y por último un tiempo político. Las diferencias con otros factores de poder (sindicatos, partidos políticos) como también dentro de las propias Fuerzas Armadas hicieron que el gobierno no pudiera alcanzar sus metas, en especial aquellas referidas a los aspectos social y político. A ello se sumaba la presencia cada vez más cercana de Perón que, desde el exilio, se embanderaba en una tendencia revolucionaria identificada con amplios sectores de la juventud.

${ }_{12}$ ROUQUIÉ, Alain, Poder militar y sociedad política en la Argentina, t. II, Buenos Aires, Hispamérica, 1986, p. 212. 


\section{Entre humor político y social: la revista «Tía Vicenta»}

«Tía Vicenta» se empezó a publicar en el año 1957 y se cerró por la clausura del entonces presidente Onganía en el año 1966. La revista de humor hacía desfilar por sus páginas a los personajes de la época: Frondizi, Illia, Alsogaray, Onganía, y tantos otros satirizados por el humor inteligente del equipo editorial. Asimismo, caracterizaba en clave humorística las peculiaridades de grupos, personajes y tipos sociales de la sociedad argentina. Para la época en que existió fue un éxito editorial que comenzó con una tirada de 50.000 ejemplares hasta llegar a los casi 450.000 en su último número.

Dirigida por Juan Carlos Colombres (Landrú), «Tía Vicenta» fue una de las revistas que revolucionó las formas de hacer humor en esos años ${ }^{13}$. Desde fines de los años '30 y principios de los '40, dos son las publicaciones que marcaron la época: «Rico Tipo» (dirigida por Divito) y «Patoruzú» (dirigida por Dante Quinterno). Las mismas hegemonizaron el humor gráfico argentino durante los últimos años del peronismo pero no supieron salir de la repetición de arquetipos. Así, entre la «revolución libertadora» y los primeros años del gobierno democrático de Arturo Frondizi se dio una renovación decisiva o el «renacimiento del humor político» ${ }^{14}$.

En esa línea que marcó el nuevo humor argentino de la década de 1960 se ubica el nacimiento de la revista. Landrú para su creación se apoyó en una “doble apuesta”, por un lado pretendía «desplazar el absurdo de lo cotidiano al terreno de la política» y, por el otro, «responder a una pregunta sencilla: si lo están haciendo en el Maipo o El Nacional ${ }^{15}$, ¿por qué no hacerlo en una revista?»16. Así, imaginó una revista libre, es decir, sin secciones fijas que mecanizaran la lectura sino con cambios constantes. La idea era que cada número fuera una "sorpresa" para el lector. Todas las semanas, la revista se "disfrazaba de" y presentaba portadas y formatos diferentes que iban desde el de la revista «Claudia» a la Selecciones del Readers Digest pasando por «Ahora» o «La Chacra» entre tantos ${ }^{17}$.

\footnotetext{
${ }_{13}$ Comenzó como una revista semanal hasta noviembre de 1960. A partir de ese momento fue quincenal. En el año 1964 fue mensual y desde el año 1965 pasó a formar parte del diario $E l$ Mundo como suplemento dominical. Información extraída de: GANDOLFO, Amadeo, "Tía Vicenta, entre Frondizi y Onganía (1957-1966)», in Caiana. Revista electrónica de Historia del Arte y Cultura Visual del Centro Argentino de Investigadores de Arte (CAIA), 2, 1/2013, pp. 113.

${ }_{14}^{14}$ RUSSO, Edgardo, La historia de Tía Vicenta, Buenos Aires, Espasa Calpe, 1994, p. 23.

15 Tanto el Maipo como el Nacional eran dos teatros destacados y representativos del espectáculo porteño.

${ }_{16}$ RUSSO, Edgardo, op. cit., pp. 42-43.

${ }^{17}$ Las revistas mencionadas eran de circulación masiva y se especializaban en temáticas diferentes.
} 
El subtítulo que aparece en las portadas: "revista del nuevo humor" refleja unas líneas bien definidas que marcarán su estilo. Por un lado, la política y sus representantes estarán personificadas en un sainete crítico y humorístico por presidentes, militares y representantes de partidos políticos. Algunos serán los favoritos de la revista en los primeros números, así desfilarán entre sus páginas y portadas Rojas, Aramburu, Pinker, el perro olvidado por Peron, Frondizi, Alfredo Palacios y Krieger Vasena. A ellos, se sumarán con el paso de los años: Guido, Illia, Alsogaray, Onganía. En cuanto a la prohibición de nombrar a Perón, dispuesta por el decreto 4161, Landrú buscó la forma de que aparezca en la publicación. A través de una viñeta bajo el título «Aumentativos no son/aunque terminen en on», presentó los siguientes ejemplos ilustrados: buzo/ buzón - pelo/pelón - lecho/lechón coraza/corazón - velo/velón - pera/decreto $4161^{18}$.

Por otro lado, se observa una segunda línea que va más allá de las figuras y escenas políticas: el "humor social". Al respecto, nos referimos a una práctica comunicativa que se ancla en los "campeonatos" que hicieron desfilar por las páginas de la revista a "mersas, caqueros, pirujas, gordis, ratitas, gente in y out". De esta forma, la sociedad toda podía reconocerse en aquellos arquetipos característicos de esos años e inclusive participar de los concursos eligiendo al máximo exponente de cada una de las categorías. Uno de los "mersas" más votado durante varios números fue el cantante Palito Ortega, exponente de la llamada "nueva ola"19. La identificación del cantante, implicaba una valoración social realizada por los mismos editores mientras que este tipo de detalles eran la representación de un imaginario social en el cual existían "caqueros" y "mersas"20, "gente in y out", con consumos culturales específicos.

A los campeonatos, se sumaba una galería de personajes en cuadros de historieta que aparecían con regularidad: el señor Porcel (discutidor empedernido); la familia Cateura (una versión inesperada de un sector de la clase media cuentapropista analizada a través de esta familia cuyos padres eran identificados como violentos, ignorantes, ambiciosos pero sobre todo peronistas); Rogelio, el hombre que razonaba

${ }^{18}$ Tía Vicenta, 5, septiembre de 1957.

19 Según Valeria Manzano, la expresión la "nueva ola" se empezó a utilizar en el lenguaje periodístico y popular entre fines de los años '50 y principios de los '6o. La misma se aplicaba a "estilos musicales, como el rock o el twist, que constituyeron los canales fundamentales para la transformación del consumo, el ocio y las modas juveniles". Véase: MANZANO, Valeria, «Ha llegado la 'nueva ola': música, consumo y juventud en la Argentina, 1956-1966», in COSSE, Isabella, FELITTI, Karina, MANZANO, Valeria, Los ' $6 o$ de otra manera. Vida cotidiana, género y sexualidades en la Argentina, Buenos Aires, Prometeo, 2010, p. 19.

${ }_{20} \mathrm{Al}$ respecto hemos avanzado en el análisis de estas tipologías juveniles. Véase BARTOLUCCI, Mónica, FAVERO, Bettina, «Caqueros, mersas y degeneraditos. Una mirada alternativa a la juventud sesentista desde la revista Tía Vicenta. 1963-1966», in V Jornadas Nacionales de Historia Social, La Falda, 13-15 de mayo de 2015. 
demasiado; el detective Cuculiu y el señor Ricardo Fox. Así, el humor no atravesaba solo lo político sino la sociedad toda.

Otro ingrediente a destacar de la publicación era la gráfica, caricaturas y fotomontajes inundaban sus páginas que en cada número sorprendía y mostraba el lado más cómico de los personajes de la política argentina como también de la sociedad de entonces. La revista también fue el resultado del trabajo de muchos colaboradores, algunos jóvenes y otros ya adultos, que habían empezado sus primeros pasos o se habían consagrado en la línea del humor gráfico en los años '40 y '50. Juan Carlos Colombres se acompañó de un equipo polifacético ${ }^{21}$.

«Tía Vicenta» dejó de publicarse el 17 de julio de 1966, pocas semanas después de la asunción del general Onganía como presidente de la Nación. La revista es clausurada «por falta de respeto hacia la autoridad y la investidura jerárquica»²2, específicamente por representar al presidente como una morsa. Este suplemento dominical, que salía con el diario «El Mundo» y que había llegado a tiradas excepcionales, era condenado al silencio. «En la historia de la caricatura política nacional desfilaron el Zorro, el Burro, el Mono, el Peludo, el Gorila, el Avestruz, el Chancho, la Tortuga y otros tantos animales representando a otros tantos políticos y dando a esa transmutación un sentido direccionalmente crítico, sin consecuencias tan drásticas como la que sufrió «Tía Vicenta» por la búsqueda ingenua de la analogía que sugiere subjetivamente la apariencia física del nuevo presidente» ${ }^{23}$.

La vida de «Tía Vicenta» se dio en una época marcada por grandes cambios donde se respiraba un clima de época distinto, perceptible por la revolución cultural y la modernización. Los sesenta también fueron protagonistas de las «tensiones entre "gran arte" y "cultura menor", es decir entre producción visual e implicación política o entre práctica artística y crítica institucional» ${ }^{24}$. Así, esta publicación se involucró en la crítica humorista a los gobiernos de turno pero también le dio su espacio a la sátira social.

${ }^{21}$ Carlos del Peral (jefe de redacción), Esther Linares (secretaria de redacción), Quino y Faruk (dibujantes), Arizmendi y Garaycochea (diagramadores). A ellos se sumaban en los distintos números, dibujantes y escritores que cumplían el rol de colaboradores: Conrado Nalé Roxlo, Rogelio García Lupo, Jordán de la Cazuela, María Elena Walsh, Leda Valladares, Gerardo Sofovich, Gila, Brascó, Oski, Vilar, Sabat, César Bruto, Basurto, Gius, por mencionar sólo algunos.

${ }_{22}$ ULANOVSKY, Carlos, Paren las rotativas. Historia de los grandes radios, revistas y periodistas argentinos, Buenos Aires, Espasa, 1996, p. 175.

23 VÁZQUEZ LUCIO, Oscar, Historia del humor gráfico y escrito en la Argentina, T. 2, Buenos Aires, Eudeba, 1987, p. 349.

24 PLANTE, Isabel, «Recorridos de la Mujer Sentada. Las tiras cómicas de Copi entre París y Buenos Aires», in GENÉ, Marcela, Atrapados por la imagen. Arte y política en la cultura impresa argentina, Buenos Aires, Edhasa, 2013, p. 283. 


\section{Indicios de una "revolución" 25}

Los pueblos se ríen de lo que temen y de lo que admiran

André Maurois

El trabajo asociado al relevamiento de los números de «Tía Vicenta» ${ }^{26}$ comprendidos en el año y medio previo al golpe de Estado consistió en extraer las referencias constantes y cada vez más frecuentes de la inminencia del derrocamiento del gobierno civil, contrastándolas con la coyuntura en la que eran editadas.

Si bien el objetivo del artículo dista de analizar la postura política de la revista, es necesario remarcar que se partirá del supuesto de que su redacción no era proclive a defender la postura "golpista". Por el contrario, el análisis ha tenido como propósito observar desde el humor político, el modo en que el proceso que culminó con la autodenominada "Revolución Argentina”, era apreciado y representado en las tiras cómicas y artículos de una revista en particular. Así, es posible considerar como las publicaciones se convertían en un espejo de la "temperatura" de la política de esos años.

\footnotetext{
${ }^{25}$ En este análisis no nos adentraremos en la vinculación de la prensa gráfica con el golpe. Sobre el papel que jugaron muchos de los medios de comunicación de la época en la imagen y el posterior derrocamiento del gobierno del Dr. Illia Véase: TARONCHER, Miguel, La caída de Illia. La trama oculta del poder mediático, Buenos Aires, Vergara, 2009; MAZZEI, Daniel, Los medios de comunicación y el golpismo el derrocamiento de Illia (1966), Buenos Aires, Grupo Editor, 1997.

${ }^{26}$ Las imágenes que aparecen en el texto forman parte de la colección de la revista «Tía Vicenta» que se ubica en la Hemeroteca de la Biblioteca Nacional "Mariano Moreno", Buenos Aires, Argentina.
} 


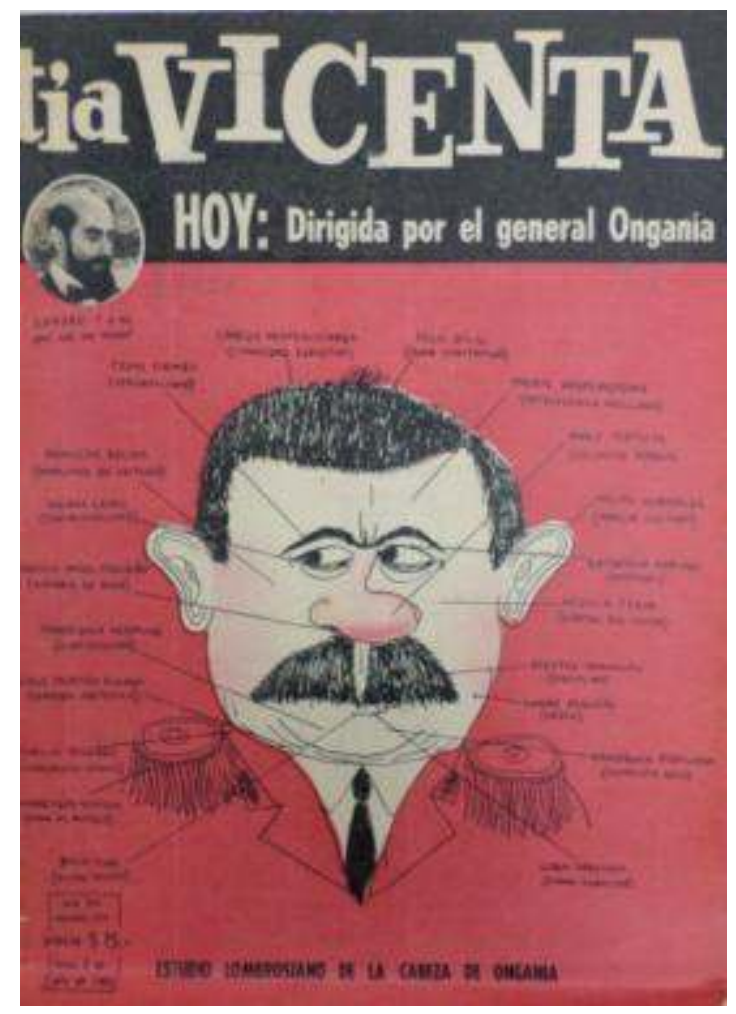

Fig. 1. «Tía Vicenta», imagen de tapa, 264, 8 de julio de 1963.

La figura de Onganía se presenta en la revista como una de sus referencias constantes y centrales desde julio de 1963, mes en que se dedica un número entero a su persona $^{27}$. A posteriori y con la restauración democrática que marcó la victoria de la Unión Cívica Radical del Pueblo (UCRP), el teniente general fue referido en numerosas ocasiones como un factor de poder con derecho a veto, es decir, quien tenía la última palabra, por encima del presidente Illia.

De esta manera en un artículo titulado "Decreto Reglamentario de la Primavera"28, en su artículo primero se deja constancia del alcance temporal de la estación aseverando que puede variar en tanto que el teniente general Onganía "disponga lo contrario”. Ese mismo mes, en el siguiente número, se muestra en una viñeta a Onganía afirmando: «El gobierno y nosotros nos llevamos a las mil maravillas» ${ }^{29}$. Sin embargo, la gestión conformada en octubre de 1963 había mantenido, desde la división de la UCR luego del golpe de Estado de 1955, mejores relaciones con la facción militar que otrora había encabezado el almirante Isaac Rojas. Tal posicionamiento chocaba con los

${ }_{27}^{27}$ Tía Vicenta, 264, julio de 1963.

${ }^{28}$ Tía Vicenta, 326, septiembre de 1965.

29 Tía Vicenta, 327, septiembre de 1965. 
intereses del grupo que comandaba las FFAA desde los enfrentamientos de septiembre de 1962 y abril de $1963^{30}$.

El creciente poder que ostentaba el Comandante en Jefe del Ejército llegó a generar polémicas de carácter internacional en el marco de la instauración de la Doctrina de Seguridad Nacional ${ }^{31}$. Tal suceso de la mano del recurso de ofrecer embajadas a oficiales retirados para alejarlos de la política nacional, no pasó inadvertido para la revista. En primer lugar, en una sección titulada "El rinconcito optimista" ${ }^{2}$ se afirma que miembros de las FFAA que habían sido designados embajadores en Santo Domingo, rechazaron sus cargos "y se quedaron en el país para seguir conspirando". Por otro lado, varios meses después se incluyó un artículo con el nombre de "Embajada se ofrece"33 donde se representa un diálogo en el que Onganía rechaza una variedad de puestos diplomáticos pues tenía «otras ofertas para cosas muy interesantes».

Tal como se puede apreciar en los párrafos anteriores, conforme la situación del gobierno radical se volvía más inestable, los sutiles, y a veces no tanto, anuncios de una intervención militar, se hacían más frecuentes. De esta forma y a través de un humor suspicaz, la revista medía la temperatura política de la época.

En septiembre de 1965, dos meses antes del pase a retiro efectivo voluntario del teniente general Onganía, una viñeta titulada Rumor ${ }^{34}$ plantea un interrogante que podría pasar desapercibido si es descontextualizado. Debajo de una imagen donde un personaje femenino le susurra a otro masculino "Onganía”, se puede leer: «¿Qué hay entre Coco Hardoy y Nélida Roca?» Esta referencia carece de sentido si no se tiene en cuenta que la vedette en ese momento estaba presentando una revista titulada «Te espero» 35 y que Emilio Hardoy era un dirigente del conservadurismo e integrante de la oposición al gobierno de turno.

$3^{30}$ ROUQUIÉ, Alain, op. cit., p. 226.

${ }^{31}$ Ibidem, p. 234.

32 Tía Vicenta, 343, enero de 1966.

33 Tía Vicenta, 357, abril de 1966.

34 Tía Vicenta, 325, septiembre de 1965.

35 SANTÁNGELO, Guillermo (comp.), «A cuarenta años del derrocamiento de Illia» in Universidad Torcuato Di Tella, junio de 2006, URL:

$<$ http://www.utdt.edu/ver_nota_prensa.php?id_nota_prensa=1159\&id_item_menu=6 > [consultado el 6 de agosto de 2015]. 


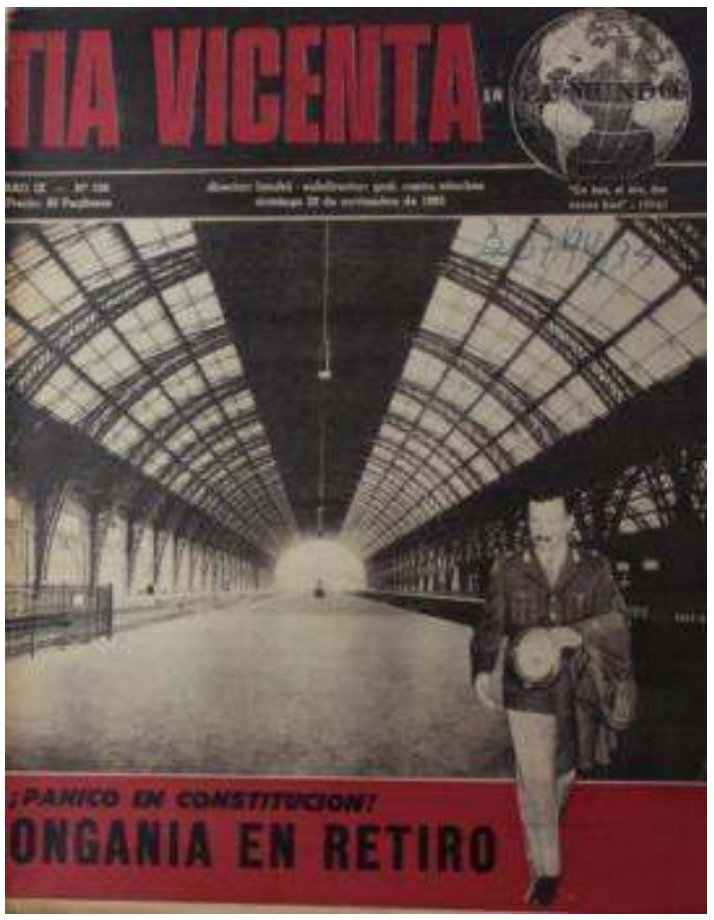

Fig. 2. «Tía Vicenta», imagen de tapa, 336, 28 de noviembre de 1965.

La designación del general Castro Sánchez (afín a Illia) como Secretario de Guerra en noviembre de 1965, llevó al general Onganía a optar por el retiro36, siendo sucedido por el general Pistarini en la comandancia del Ejército. Tales sucesos fueron leídos por la prensa como el inicio del fin para el gobierno de la UCRP37. La revista se manifestó en los dos números siguientes al hecho ${ }^{38}$ dedicando varios artículos que satirizaban la situación. En primer lugar, se muestra al general Pistarini, dándose un "golpe" de frente con Illia luego de afirmar que durante su gestión no habría "ni un solo roce con el Poder Ejecutivo". En el siguiente número varias referencias tienden a marcar el significado político del retiro. Por un lado, en la sección de chistes que suele preceder a la nota editorial se relaciona a la situación política del gobierno con una carrera automovilística. El autor anuncia la "lamentable deserción" de Onganía y la inclusión del Castro Sanchez y Pistarini, planteando el interrogante sobre si Illia y Perette llegarían "hasta el final de la carrera". Por otro lado, en la sección central se muestra una vista "en corte" con un detalle de las habitaciones de la casa de gobierno, en la que aparece una foto del retirado Comandante en Jefe como un material "en desuso". Otros dos artículos refieren a la responsabilidad del gobierno en el pase a retiro de Onganía.

${ }^{36}$ Cabe aclarar que, en esa coyuntura, estar en situación de "retiro activo voluntario" implicaba según la lógica militar, adoptada por transferencia por la sociedad civil, encontrarse en condiciones de asumir un cargo político en el gobierno.

37 ROUQUIÉ, Alain, op cit., pp. 234-235.

${ }_{38}^{8}$ Tía Vicenta, 336, noviembre de 1965 y Tía Vicenta, 337, diciembre de 1965. 
El primero de ellos es una encuesta ficticia en la que se pide la opinión de diversos miembros destacados de la gestión civil, en la que ninguno de los interpelados se refiere al hecho en cuestión. La indagación finaliza con una intervención del mismo Onganía: «Con su permiso, yo me retiro». El segundo artículo, titulado "Comunicado 201: Chau" indica, con sutileza, que el suceso habría sido una estrategia política del gobierno. En la última viñeta, una persona comenta como al despacho de Onganía «le han movido el piso».

Sobre la posición del gobierno, y de Illia en particular, en el último número de $1965^{39}$ figura una viñeta donde los conflictos ocurridos durante todo el año rodean al presidente mientras duerme.

A partir del primer número de 1966 las referencias al golpe de Estado se encuentran en casi todas las publicaciones. Las sutiles acotaciones a una intervención de las FFAA existentes hasta el momento, se hacen abiertas desde enero. En un apartado que a su vez es nota de tapa ${ }^{40}$ se anuncia que las próximas elecciones serían anuladas. En números posteriores es posible rastrear diversas referencias a la isla Martín García ${ }^{41}$. Por un lado, un artículo titulado "Salutaciones para 1966"42 que simula, entre otras, una carta con deseos de Illia para el año que comienza, asevera que el año 1967 podría iniciarlo en la isla. Varias semanas después en una solicitada titulada "iSepa la ciudadanía!”, firmada nuevamente por el presidente se alega que Martín García es un fantasma "inventado por los militares para asustar a los presidentes y obligarlos a marcar el paso"43. A su vez, a fines de febrero se afirma que los presidentes argentinos suelen residir en la isla «durante los últimos años de su mandato».44

Sobre la fecha del golpe la revista también realizó varias especulaciones. Por un lado, el 30 de enero, en la página central, hay un calendario en cuyo mes de abril se muestra un sujeto calzado con zapatos, dejando el sillón presidencial para ser reemplazado por otro que viste botas. A su vez en el mes de mayo, en la página de chistes que sigue a la tapa se hacen diversas referencias a un golpe de Estado. Entre ellas, se caricaturiza al presidente recibiendo un "golpe" a su puerta y al general Onganía afirmando que 1967 tendría solo “once meses”45.

\footnotetext{
39 Tía Vicenta, 340, diciembre de 1965.

4 Tía Vicenta, 341, enero de 1966.

${ }^{41}$ La isla Martín García se encuentra en el Río de la Plata y es conocida por ser una prisión que albergó desde el primer golpe de estado del siglo XX a algunos de los presidentes democráticos salientes. Algunos de los mandatarios trasladados allí fueron Yrigoyen, Perón y Frondizi.

42 Tía Vicenta, 342, enero de 1966.

43 Tía Vicenta, 345, enero de 1966.

44 Tía Vicenta, 349, febrero de 1966.

45 Tía Vicenta, 360, mayo de 1966.
} 


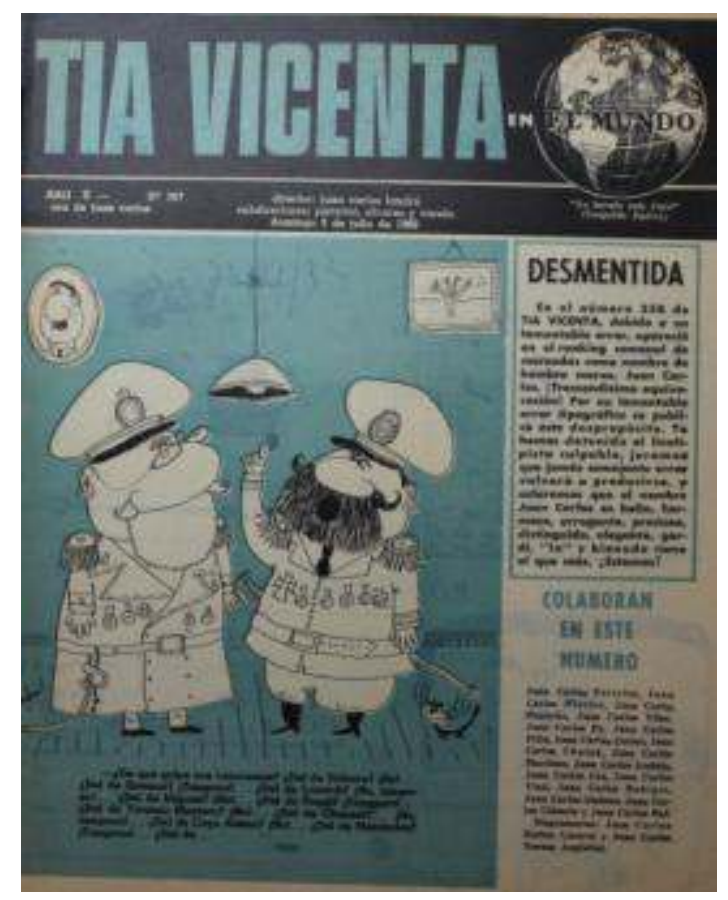

Fig. 3. «Tía Vicenta», imagen de tapa, 367, 3 de julio de 1966.

Rouquié afirma que la campaña golpista, cuyas causas deben ser rastreadas desde mediados de 1965 tiene su inicio en marzo de 1966. A partir de ese mes, los integrantes de las FFAA comenzaron a hablar abiertamente de la necesidad de intervenir al gobierno civil. Según el autor la posibilidad de una victoria peronista en los comicios del año siguiente motivó la decisión ${ }^{46}$. La revista, a la zaga de los acontecimientos, publicó un "Estatuto del golpe" 47 en el cual nuevamente se hace referencia a la incompetencia del gobierno y a las conspiraciones dentro del Ejército. El número anterior al suceso ${ }^{48}$ se inició con una invitación para participar de una apuesta sobre la fecha y división dentro de las fuerzas de defensa y seguridad que daría el golpe.

El devenir de los acontecimientos y la destitución de Illia no pusieron fin a las actividades de la revista. El régimen de facto instaurado por las FFAA fue tratado con la misma sátira que el gobierno democrático que lo precedió. Sin embargo en una dictadura de tinte "apolítico" y supresor de la opinión pública, fueron las mismas características de la revista las que marcaron su censura.

${ }^{46}$ ROUQUIÉ, Alain, op. cit., p. 248.

47 Tía Vicenta, 353, marzo de 1966.

48 Tía Vicenta, 366, junio de 1966. 


\section{A modo de conclusión}

«Tía Vicenta incursionará en el terreno del compromiso y del no compromiso, brindando en líneas generales una imagen que puede ser considerada, según la óptica desde que se la mire, como tolerante, concesiva, comprometida, prescindente, prejuiciosa, impertinente o meramente frívola y divertida» 49 .

A través del uso de una revista de humor político hemos querido observar la forma en que se fue "esperando" la revolución de 1966. Desde mediados de 1965, es decir, casi un año antes del golpe militar, la revista presentaba indicios de que el gobierno de Arturo Illia no cumpliría su mandato completo. A ello se sumaba la importancia que fue tomando la figura del general Onganía desde el año 1963, reflejo de su influencia en el sector militar que lideraba. Estos síntomas eran tomados de la realidad política de aquellos años en la que desfilaban los encuentros y desencuentros entre militares y políticos de distintos partidos. Ahora bien, la revista contaba con materia prima para elaborar una publicación, lo interesante es ver la forma en que se trataban estos temáticas y rumores en torno al golpe de estado desde el humor. Ante esto podemos preguntarnos si la revista ¿era políticamente ambigua? O al contrario ¿marcaba una línea? Somos conscientes que cualquier medio de comunicación es formador de opinión por lo tanto creemos que el ambiente pre-golpista que se observa satirizado en las distintas viñetas era por un lado un espejo de la realidad argentina pero por el otro podía llegar a ejercer cierta influencia sobre la opinión pública. Cabe destacar la forma o la manera en que Colombres y sus colaboradores, supieron amalgamar absurdo, humor negro, chiste político y frivolidad para representar una situación o una época.

En esta reflexión no queremos caer en la idea común que una revista pudo haber gestado el apoyo de parte de la población a un golpe de estado, no es nuestro objetivo de trabajo. Lo que si hemos querido rastrear y analizar fue el lugar que ocupó el general Onganía en la publicación y por ende la espera sentenciada de un golpe militar, hecho que se repetía casi sistemáticamente desde el año 1930.

Son muchos los interrogantes que nos quedan por responder, este ha sido simplemente un primer acercamiento al modo en que el proceso que culminó con la autodenominada "Revolución Argentina" era apreciado y representado en las tiras cómicas y artículos de una revista en particular, el mismo se profundizará con nuevas preguntas y cuestiones.

49 Véase: RIVERA, Jorge, Humorismo y costumbrismo (1950-1970), Buenos Aires, CEAL, 1984. 


\section{${ }^{*}$ Los autores}

Bettina Favero es Profesora y Licenciada en Historia por la Universidad Nacional de Mar del Plata y Doctora en Historia por la Universidad Nacional del Centro (Tandil). Desde el año 1999 hasta el 2006 fue becaria doctoral y posdoctoral del CONICET. Entre los años 2008 y 2009 consiguió una beca superior de posdoctorado de la Agencia Nacional de Promoción Científica y Tecnológica. En el año 2007 recibió el premio "tesi di Ph.D discussa in un'università straniera". Concorso del Centro Altreitalie sulle Migrazioni Italiane e la Fondazione Agnelli, Torino. En el año 2011 ingresó como investigadora asistente en la carrera de Investigador del CONICET. Desde hace más de 10 años es docente en la Facultad de Humanidades, UNMdP. Ha publicado libros, artículos en revistas científicas especializadas y capítulos de libros en diversas compilaciones de nivel local, nacional e internacional.

URL: < http://www.studistorici.com/progett/autori/\#Favero >

Francisco Mosiewicki es Profesor en Historia por la Universidad Nacional de Mar del Plata. En la actualidad está realizando su tesis de Licenciatura. Desde el año 2013 hasta el 2015 fue becario CIN. Fue ayudante alumno de la Facultad de Humanidades durante los años 2013 y 2014. Ha publicado artículos y reseñas de libros en revistas científicas especializadas.

URL: < http://www.studistorici.com/progett/autori/\# Mosiewicki >

\section{Per citare questo articolo:}

FAVERO, Bettina, MOSIEWICKI, Francisco, «La revolución Argentina es cosa seria: el humor político en la coyuntura del golpe de estado de junio de 1966», Diacronie. Studi di Storia Contemporanea : Le dittature militari: fisionomia ed eredità politica, 29/12/2015,

URL:< http://www.studistorici.com/2015/12/29/favero-mosiewicki_numero_24/ >

Diacronie Studi di Storia Contemporanea $\approx$ www.diacronie.it

Risorsa digitale indipendente a carattere storiografico. Uscita trimestrale. redazione.diacronie@hotmail.it

Comitato di redazione: Jacopo Bassi - Luca Bufarale - Elisa Grandi - Antonio César Moreno Cantano - Deborah Paci - Fausto Pietrancosta - Alessandro Salvador - Matteo Tomasoni - Luca Zuccolo

Diritti: gli articoli di Diacronie. Studi di Storia Contemporanea sono pubblicati sotto licenza Creative Commons 3.0. Possono essere riprodotti e modificati a patto di indicare eventuali modifiche dei contenuti, di riconoscere la paternità dell'opera e di condividerla allo stesso modo. La citazione di estratti è comunque sempre autorizzata, nei limiti previsti dalla legge. 